\title{
Rare Left-Sided Gastrochisis with Bifid Umbilical Cord
}

\author{
Patrick Danso ${ }^{*}$, Boateng Nimako1,2, Michael Amoah ${ }^{1,2}$, Abiboye Chinedum Yifieyeh ${ }^{1,2,3}$, \\ Robert Sagoe',2,3, Anthony Davor ${ }^{1,2}$, Samuel Gyasi Brenu', Jane Acquaye1 \\ ${ }^{1}$ Directorate of Surgery, Komfo Anokye Teaching Hospital, Kumasi, Ghana \\ ${ }^{2}$ Pediatric Surgery Unit, Directorate of Surgery, Komfo Anokye Teaching Hospital, Kumasi, Ghana \\ ${ }^{3}$ Department of Surgery, School of Medicine and Dentistry, Kwame Nkrumah University of Science and Technology, Kumasi, \\ Ghana \\ Email: maame.jenny@yahoo.com
}

How to cite this paper: Danso, P., Nimako, B., Amoah, M., Yifieyeh, A.C., Sagoe, R., Davor, A., Brenu, S.G. and Acquaye, J. (2021) Rare Left-Sided Gastrochisis with Bifid Umbilical Cord. Open Access Library Journal, 8: e8073.

https://doi.org/10.4236/oalib.1108073

Received: October 13, 2021

Accepted: November 2, 2021

Published: November 5, 2021

Copyright (C) 2021 by author(s) and Open Access Library Inc.

This work is licensed under the Creative Commons Attribution International License (CC BY 4.0).

http://creativecommons.org/licenses/by/4.0/

\begin{abstract}
Gastroschisis is condition characterized by a congenital herniation of abdominal viscera through a full thickness defect in the anterior abdominal wall, usually to the right of the umbilicus, with no protective covering. Left-sided gastroschisis, in which the defect occurs on the left side of the umbilical cord, is very rare compared to the common right-sided gastroschisis and it is usually associated with high incidence of other congenital anomalies. This is a case report of a newborn female referred from a district hospital with an abdominal wall defect that was not identified on antenatal ultrasound, with features consistent with a left-sided gastroschisis and a bifid umbilical cord at its fetal attachment site. Extensive research of literature reviews on left-sided gastroschisis showed a little over thirty (30) cases have been reported so far.
\end{abstract}

\section{Subject Areas}

Surgery \& Surgical Specialties

\section{Keywords}

Gastroschisis, Left-Sided, Bifid Umbilical Cord, Abdominal Wall Defect

\section{Introduction}

Gastroschisis is a congenital anomaly typically characterized by anterior abdominal wall defect on the right of a normal umbilicus with herniation of abdominal contents through it. It was reported to have an incidence of $0.3-1$ per 10,000 live births by Suver and colleagues in 2008 [1], but recent literatures have quoted increased figures of 2 - 5 per 10,000 live births [2]. Left-sided gastroschi- 
sis is a relatively rare condition with only few reported cases in literature [2] (Table 1). We report a case of a 38-week 4-day old female delivered via caesarean section who presented with a left-sided gastroschisis associated with a bifid umbilical cord and suspected cardiac anomaly.

\section{Case Report}

The baby was five-hour-old female, delivered via caesarean section on account of two (2) previous caesarean sections at thirty-eight (38) weeks and four (4) days gestation with APGAR scores of 6/10, 7/10 in the first (1st) and fifth (5th) minutes of birth respectively. Birth weight was $3000 \mathrm{~g}$. Newborn examination revealed, anterior abdominal wall defect with evisceration of small and large bowel loops, uterine tubes, and stomach. The herniated organs were covered with a plastic bag and quickly referred to our tertiary hospital's Neonatal Intensive Care Unit (NICU) for further management. At NICU, further examination revealed a female baby, not pale, anicteric, mild peripheral cyanosis, and anterior abdominal wall defect (size of about $4 \mathrm{~cm}$ ) on the left side of a bifid umbilical cord at its attachment site with evisceration of small bowel loops, stomach, uterine tubes and ovaries with no covering membrane (Figure 1). The eviscerated organs were edematous, thickened, had meconium stains and fibrinoid adhesive bands on their surfaces. Baby was nursed under radiant warmer, venous access secured and maintenance fluid, intravenous antibiotics and analgesic given. A nasogastric tube was passed to decompress the bowels and eviscerated organs cleaned with warm saline and examined for perforations, necrosis, atresia and malrotation, but none was found. Alexis Wound Protector for size $2-4 \mathrm{~cm}$ incision was carefully applied on the eviscerated organs as a silo (Figure 2) and vitals post the procedure were normal. Monitoring continued and twice daily reduction of the eviscerated organs was planned, with hydration and total parenteral nutrition. On day three post silo application, baby was noticed having respiratory distress and chest $\mathrm{x}$-ray showed massive cardiomegaly pointing to congenital cardiac anomaly (Figure 3), but she died before echocardiogram could be done.

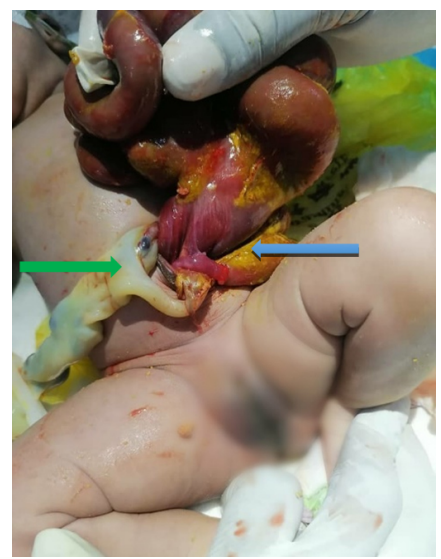

Figure 1. GREEN ARROW-bifid umbilical cord attachment to skin. BLUE ARROW-Defect on the left side of the bifid cord. 


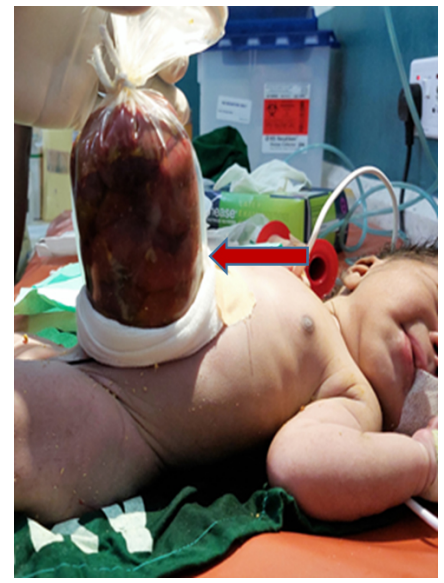

Figure 2. RED ARROW-Silo mounted with an Alexis Wound Protector.

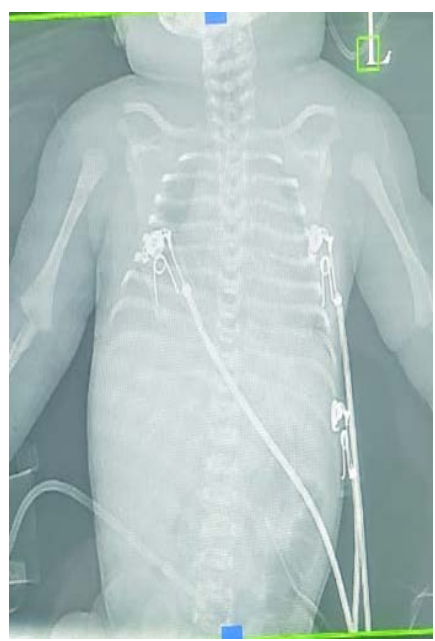

Figure 3. Chest $\mathrm{x}$-ray showing the cardiomegaly.

Table 1. Summary of left-sided gastrochisis in literature.

\begin{tabular}{|c|c|c|c|c|c|c|}
\hline Case no. & Year & Authors & $\begin{array}{c}\text { Gestational age } \\
\text { (week) }\end{array}$ & Week (g) & Sex & Associated anomalies \\
\hline 1 & 1988 & Blair et al. & - & - & M & None \\
\hline 2 & 1989 & Hirthler et al. & 27 & 900 & $\mathrm{~F}$ & Hyaline membrane disease \\
\hline 3 & 1989 & Hirthler et al. & Term & 3800 & $\mathrm{~F}$ & None \\
\hline 4 & 1993 & Toth et al. & 35 & 1540 & $\mathrm{~F}$ & None \\
\hline 5 & 2000 & Thepcharoennirund et al. & 36 & 1700 & $\mathrm{~F}$ & None \\
\hline 6 & 2000 & Thepcharoennirund et al. & 40 & 2450 & M & None \\
\hline 7 & 2001 & Pringle KC & 34 & 2065 & M & $\begin{array}{l}\text { Left testis herniating } \\
\text { through defect }\end{array}$ \\
\hline 8 & 2002 & Fraser et al. & 28 & 880 & $\mathrm{~F}$ & None \\
\hline 9 & 2002 & Ashburn et al. & Term & 2800 & M & None \\
\hline
\end{tabular}




\section{Continued}

\begin{tabular}{|c|c|c|c|c|c|c|}
\hline 10 & 2004 & Ameh et al. & Term & - & M & None \\
\hline 11 & 2004 & Orpen et al. & Term & 2604 & $\mathrm{~F}$ & $\begin{array}{l}\text { Pseudoextrophy, ASD, PDA, } \\
\text { ureteral reflux }\end{array}$ \\
\hline 12 & 2004 & Wang et al. & - & 1700 & - & Situs inversus \\
\hline 13 & 2004 & Yoshioka et al. & 38 & 2815 & $\mathrm{~F}$ & None \\
\hline 14 & 2004 & Gow et al. & 34 & - & $\mathrm{F}$ & Necrosis of herniated bowel \\
\hline 15 & 2006 & Prasun et al. & 39 & 3100 & $\mathrm{~F}$ & None \\
\hline 16 & 2007 & Suver et al. & 24 (terminated) & 2200 & M & Multicystic renal dysplasia \\
\hline 17 & 2008 & Suver et al. & 34 & 2200 & $\mathrm{~F}$ & $\begin{array}{c}\text { Jejunal atresia, microcolon, } \\
\text { absent corpus callosum, optic } \\
\text { dysplasia, panhypopituitarism, } \\
\text { intestinal atresia }\end{array}$ \\
\hline 18 & 2008 & Suver et al. & 35 & 2200 & $\mathrm{~F}$ & $\begin{array}{l}\text { Cerebral arteriovenous } \\
\text { malformations }\end{array}$ \\
\hline 19 & 2008 & Suver et al. & 34 & 2200 & $\mathrm{~F}$ & ASD, Pulmonary valve stenosis \\
\hline 20 & 2010 & Punia & 26 (FDIU) & & M & Meromelia of all four limbs \\
\hline 21 & 2012 & Patel et al. & 34 & 2160 & $\mathrm{~F}$ & Small left colon syndrome \\
\hline 22 & 2012 & Shi & 35 & 1920 & M & $\begin{array}{l}\text { Liver/Stomach/Spleen herniation, } \\
\text { VSD scoliosis, small chest }\end{array}$ \\
\hline 23 & 2013 & Mandella et al. & Term & 2260 & M & PDA \\
\hline 24 & 2013 & Patel et al. & 37 & 2740 & M & $\begin{array}{l}\text { Hypoplastic left hemiscrotum, } \\
\text { atrophic left testis }\end{array}$ \\
\hline 25 & 2015 & Shin et al. & 35 & 1970 & M & $\begin{array}{l}\text { PDA, ASD, peripheral } \\
\text { pulmonary stenosis }\end{array}$ \\
\hline 26 & 2015 & Hombalker & 2400 & 2400 & M & $\begin{array}{l}\text { Cecal agenesis, short gut, } \\
\text { malrotation }\end{array}$ \\
\hline 27 & 2017 & Singh & Term & 2000 & $\mathrm{~F}$ & Meckel's diverticulum \\
\hline 28 & 2017 & Rahul & Term & - & $\mathrm{F}$ & $\begin{array}{l}\text { Intestinal atresia, perforated } \\
\text { proximal ileum }\end{array}$ \\
\hline 29 & 2017 & Litman & 34 & 2190 & $\mathrm{~F}$ & $\begin{array}{l}\text { Persistent superior vena cava, } \\
\text { left talipes equinovarus deformity, } \\
\text { hypoplastic right third digit, right } \\
\text { supernumerary } 4^{\text {th }} / 5^{\text {th }} \text { digit }\end{array}$ \\
\hline 30 & 2017 & Kalenga et al. & - & - & $\mathrm{F}$ & None \\
\hline 31 & 2017 & Soomro et al. & 36 & 1700 & $\mathrm{~F}$ & Unspecified heart murmur \\
\hline 32 & 2020 & Muta et al. & 35 & 2606 & $\mathrm{~F}$ & None \\
\hline 33 & 2020 & Muta et al. & 36 & 2014 & M & Umbilical hernia \\
\hline 34 & 2021 & Cannon et al. & 41 & 3290 & $\mathrm{~F}$ & None \\
\hline
\end{tabular}

Table adopted from [2]. 


\section{Discussion}

Gastroschisis is a congenital anomaly in which there is an anterior abdominal wall defect that occurs in utero, through which there is herniation of intra-abdominal viscera into the amniotic sac [3] [4]. The anomaly may be associated with non-rotation of the bowel and other intestinal abnormalities, such as atresia, perforation, and infarction, resulting from midgut volvulus or vascular thrombosis [4] [5]. All or a portion of the midgut is usually herniated through the defect (Figure 1). In addition, the stomach, urinary bladder, and, in females, the fallopian tubes and ovaries may also be extracelomic [4]. Risk factors observed to be involved in the development of gastroschisis include young maternal age, infections such as Urinary Tract Infection (UTI) in the first trimester, maternal use of tobacco and vasoactive agents/drugs such as cocaine, ephedrine, amphetamine etc. during pregnancy [2] [4] [5].

There are several theories which seek to explain the development of gastroschisis, among them are the vascular disruption, the early abdominal wall malformation and yolk sac failure theories. The vascular disruption theory describes a vascular accident of the right omphalomesenteric artery or early involution of the right umbilical vein which causes infarction and weakness of the cord base and surrounding wall leading to eventual rupture with herniation of viscera in utero [2] [6]. Proponents of the early abdominal wall formation theory explain the development of the disease from failure of mesenchymal differentiation within the right lateral fold of the abdominal wall and subsequent resorption of the ectoblastic layer [6]. All these theories postulate why the defect mostly occurs on the right.

Left-sided gastroschisis is very rare compared to the classical right-sided gastroschisis, with a little over thirty-four (34) cases reported so far in literature [2]. Females made up most of these reported cases (75 percent) [5]. Despite several postulations, none of the current theories of the embryogenesis of gastroschisis adequately explain how the defect can arise on the left [2] [7] [8] and its seemingly higher incidence among females [9]. Possible theories hypothesized include a right-to-left axis shift resulting in the occurrence of the herniation on the left instead on the commonly encountered right side and an early left umbilical vein regression [9]. Another interesting theory which also seeks to explain the embryology of gastroschisis is the prenatal rupture of an exomphalos [6] [10] [11]. Shaw in his paper titled The Myth of Gastroschisis concluded that clinical and embryologic evidence strongly suggests gastroschisis is as a result of in utero rupture of the membrane covering a hernia of the umbilical cord, either during its normal phase (fifth through tenth week of fetal life) or at a later stage in embryos in which closure of the normally formed umbilical ring has failed to take place [10]. In a report by Rickham on rupture of Exomphalos and Gastroschisis, thirteen (13) cases of antenatal rupture of exomphalos were admitted over a period of nine (9) years. The cases had features such as an opening in the abdominal wall lateral to the umbilical cord which appearsto have a normal attach- 
ment, some cases had a strip of apparently normal skin between the opening and the attachment of the umbilical cord, and some had remnants of the exomphalos sac attached to part or whole of the circumference of the abdominal opening and had identical features like those without remnant of sac. Also, all their cases had the opening on the right of the umbilicus. Based on the findings from his cases, he asserted that, rupture of the exomphalos sac during intrauterine life as the etiology of gastroschisis and the position of the umbilicalvein and ligamentum teres determines thesite of the prolapse of the intestine to the right of the umbilical cord [11].

Associated congenital anomalies are uncommon in gastroschisis, however, about $14 \%$ of right sided lesion have other congenital anomalies whiles approximately $50 \%$ of those with left sided lesion have other associated congenital anomalies [1] [2] [5]. Common anomalies include cardiac defects such as ASD and PDA, intestinal anomalies such as intestinal atresia, microcolon, and herniation of other abdominal organs, and limb defects etc. Our case had a suspected cardiac anomaly, based on massive cardiomegaly found on chest x-ray (Figure 3) and a bifid umbilical cord at the fetal attachment (Figure 1).

Generally, gastroschisis patients are managed at Neonatal Intensive Care Unit and the initial therapeutic goals are focused on maintaining physiologic homeostasis with intravenous fluids, respiratory support if required, thermoregulation, and bowel protection [4] [7]. Broad spectrum antibiotic is given as prophylaxis due to possible sepsis, parenteral nutrition, passage of nasogastric tube to facilitate decompression of the bowels [7] [9]. Prompt surgical intervention is required when patient has been stabilized and well optimized [2] [7]. This could be either complete reduction of eviscerated organs with primary closure of the defect or in a staged reduction with initial placement of a prosthetic silo to permit gradual visceral reduction, followed by delayed closure [7] [10]. When feasible, primary closure can be done and this allows for quick reduction of abdominal contents, which eliminates the risk of continued injury and irritation of the organs [7]. Staged closure is preferred when complete reduction will cause physiologically intolerable increase in intra-abdominal pressure.

In our case, the patient had silo placement with daily reduction of the herniated organs and a plan of sutureless closure after reduction within five days. Post successful reduction, supportive care as earlier stated are crucial to help in survival. The overall prognosis of gastroschisis is good especially in the developed world, with survival rates exceeding 90\% [2] [11] [12]. However, in the developing world with poorly resourced health facilities survival rate is very low [12].

\section{Conclusion}

Left-sided gastroschisis is very rare compared to the classical right-sided gastroschisis and is associated with higher incidences of associated congenital anomalies with cardiac defects being the most common. It is a condition whose patho- 
genesis is still yet to be elucidated despite numerous theories postulated over the years. Survival is excellent in developed and well-resourced countries with good supportive therapy and prompt evaluation and management of concomitant derangements. This case is an example of a rare occurrence especially with the bifid cord at its insertion which may be supporting the theory of physiological hernia rupture in utero.

\section{Consent}

Written informed consent was taken from the patient's relatives for publication of this report.

\section{Authors' Contributions}

PD and RS conceptualized the study. PD, SGB and JA designed the study and drafted the original manuscript. PD wrote the case summary. RS, PD and SGB applied the silo. BN supervised the study. All other authors reviewed, edited and approved the final manuscript.

\section{Conflicts of Interest}

The authors declare no conflicts of interest.

\section{References}

[1] Suver, D., Lee, S.L., Shekherdimian, S. and Kim, S.S. (2008) Left-Sided Gastroschisis: Higher Incidence of Extraintestinal Congenital Anomalies. The American Journal of Surgery, 195, 663-666. https://doi.org/10.1016/j.amjsurg.2007.12.042

[2] Cannon, R., Mitzner, A. and Whitehouse, J. (2021) Rare Left-Sided Gastroschisis with Isolated Omental Herniation. Journal of Pediatric Surgery Case Reports, 71, Article ID: 101925. https://doi.org/10.1016/j.epsc.2021.101925

[3] Gamba, P. and Midrio, P. (2014) Abdominal Wall Defects: Prenatal Diagnosis, Newborn Management, and Long-Term Outcomes. Seminars in Pediatric Surgery, 23, 283-290. https://doi.org/10.1053/j.sempedsurg.2014.09.009

[4] Schwartz, M.Z. and Timmapuri, S.J. (2021) Gastroschisis. In: Davenport, M., Geiger, J.D., Hall, N.J. and Rothenberg, S., Eds., Rob \& Smith's Operative Pediatric Surgery, 8th Edition, CRC Press, Boca Raton, 646-671.

[5] Corey, K.M., Hornik, C.P., Laughon, M.M., McHutcison, K., Reese, C.H. and Smith, B.P. (2014) Frequency of Anomalies and Hospital Outcomes in Infants with Gastroschisis and Omphalocele. Early Human Development, 90, 421-424. https://doi.org/10.1016/j.earlhumdev.2014.05.006

[6] Beaudoin, S. (2018) Insights into the Etiology and Embryology of Gastroschisis. Seminars in Pediatric Surgery, 27, 283-288. https://doi.org/10.1053/j.sempedsurg.2018.08.005

[7] Skarsgard, E.D. (2016) Management of Gastroschisis. Current Opinion in Pediatrics, 28, 363-369. https://doi.org/10.1097/MOP.0000000000000336

[8] Litman, E.A., Robinson, T.D., Munshi, U.K. and Whyte, C. (2018) Left-Sided Gastroschisis: A Case Report and Review of the Literature. Journal of Pediatric Surgery Case Reports, 36, 50-53. https://doi.org/10.1016/j.epsc.2018.07.001 
[9] Masden, T., Moores, D.C. and Radulescu, A. (2020) A Rare Combination of Left-Sided Gastroschisis and Omphalocele in a Full-Term Neonate: A Case Report. American Journal of Case Reports, 21, 1-5. https://doi.org/10.12659/AJCR.923301

[10] Shaw, A. (1975) The Myth of Gastroschisis. Journal of Pediatric Surgery, 10, 235-244. https://doi.org/10.1016/0022-3468(75)90285-7

[11] Rickham, P.P. (1963) Rupture of Exomphalos and Gastroschisis. Archives of Disease in Childhood, 38, 138-141. https://doi.org/10.1136/adc.38.198.138

[12] Fraser, N. and Crabbe, D.C.G. (2002) An Unusual Left-Sided Abdominal-Wall Defect. Pediatric Surgery International, 18, 66-67.

https://doi.org/10.1007/s003830200016 